\title{
1 Equity-oriented Criteria for Project Prioritization in Regional Transportation Planning
}

3 Agustina Krapp

4 Previous Affiliation: University of Illinois at Urbana-Champaign

5 Current Affiliation: Project Assistant

6 Asociación Sustentar

7 Buenos Aires, Argentina

8 akrapp2@illinois.edu

10 Jesus M. Barajas

11 Institute of Transportation Studies

12 University of California, Davis

13 One Shields Ave., Davis, CA 95616

14 jmbarajas@ucdavis.edu

15 ORCID: 0000-0001-8966-5778

17 Audrey Wennink

18 Director of Transportation

19 Metropolitan Planning Council

20140 S. Dearborn St., Suite 1400, Chicago, IL 60603

21 awennink@metroplanning.org

23 Word count: 6,499 words +3 tables +1 figure $=7,499$ words

24 Submitted July 29, 2020

25 Revised November 23, 2020; February 8, 2021

26 Funding information: This project was supported by a grant from the Chicago Community

27 Trust

28 Data accessibility: The data used for this study are publicly available.

29 This is the author's accepted version of an article published in Transportation Research Record.

30 Please cite as: Krapp, Agustina, Jesus M. Barajas, and Audrey Wennink. 2021. "Equity-Oriented

31 Criteria for Project Prioritization in Regional Transportation Planning." Transportation Research

32 Record. https://doi.org/10.1177/03611981211001072. 


\section{ABSTRACT}

2 Transportation inequities, consequences of decades of auto-oriented planning alongside

3 discriminatory land-use and transportation planning and policy decisions resulting from

4 structural racism, severely impact opportunities for people of color and other marginalized

5 populations. While a growing body of work has examined inequities with respect to long-range

6 transportation planning, less research examines how equity is incorporated in short-term

7 planning processes via the Transportation Improvement Program. This research reviewed how

8 the metropolitan planning organizations (MPOs) that serve the 40 largest US urbanized areas

9 used equity-based criteria for transportation project prioritization in regional planning. Just over

10 half deployed at least one equity criterion for allocating transportation funds, which fell into one

11 of six categories with varying degrees of complexity and potential for impact. While most MPOs

12 included equity in their prioritization criteria, the methods could be improved to better align with

13 more complete definitions of transportation equity, focusing on how targeted groups are defined,

14 more comprehensive methods for equity evaluation, and an increase in the weight that equity is

15 given in prioritization. MPOs and other agencies implementing transportation projects should

16 adopt a justice-oriented framework for project prioritization that ensures that projects first

17 affirmatively remedy historical inequities and work with affected communities to adopt

18 appropriate and meaningful solutions. 


\section{INTRODUCTION}

Transportation inequities in the United States are consequences of historical and contemporary racism, discriminatory public policies and private practices, inequitable funding and unequal representation in decision-making processes that have socially and spatially shaped metropolitan areas. During the 20th century, auto-oriented planning segregated neighborhoods, hollowed out communities of color, and left people without cars inferior access, all while promising progress and mobility for those upon whom the benefits of such a system were conferred (1-4). And transportation is just one in a set of factors contributing to broader societal inequities - housing discrimination, for example, is a major cause of the Black/white wealth gap (4). But over the past several decades, entrenched planning bias toward automobility has started to recede and metropolitan planning organizations (MPOs), which coordinate regional planning in the United States, have sought to address both modal and social inequities in their planning and programming (5). All transportation organizations receiving federal funding, including MPOs, must follow established guidance for conducting equity analyses $(6,7)$. Prior research has focused on critically assessing how long range transportation plans (LRTPs) perform with respect to equity by examining metrics, process, and plan content (8-12). But comparatively less work has examined the process by which stakeholders identify LRTP projects that will receive funding for implementation in the short-term. This process is often not as public as the visioning around long-term planning but can have more immediate impacts on access and equity in the region.

We address this gap in scholarship by asking how MPOs consider transportation equity during project prioritization when developing the Transportation Improvement Program (TIP) for short-term investments. We examined documentation for the MPOs that serve the 40 largest urbanized areas and categorized their project selection methods for their potential impact on equity. We found that just over half of MPOs used equity as one of the prioritization criteria, but most used a simple definition of equity that only verified proximity of transportation investments to locations where communities of concern were concentrated. The findings help inform recommendations for planning practice, including how MPOs might adopt methodologies that place equity at the center of the prioritization process.

\section{LITERATURE REVIEW}

\section{Metropolitan transportation planning and decision making}

MPOs have an important role in transportation planning in the United States. Authorized by federal law in 1962, they were established to coordinate regional mobility priorities through a comprehensive, cooperative, and continuing planning process to ensure the receipt of federal funds for continued investment (13). Visioning of the future is documented in the LRTP, which lists regional priorities and projects over a planning horizon of 20 years or more. Short-term objectives are provided in the TIP, which identifies the funded projects that will be implemented over the next four years and must be consistent with the LRTP. Both documents must be fiscally constrained, or have potential and actual funding sources identified. While LRTPs and TIPs represent regional needs, most money available for transportation projects comes through the state, ${ }^{1}$ and regional TIPs are folded into statewide TIPs. Competing goals may cause confusion

\footnotetext{
${ }^{1}$ An increasing share of money, especially for transit, comes from local sources in the form of local option sales taxes or bonds. In $2014,29 \%$ of highway revenue and $49 \%$ of transit revenue was locally generated (14). Roughly $\$ 40$ billion in funding for transportation was approved through local ballot measures in 2018 (15).
} 
and conflict between the two entities (16). And because projects are often tied to specific sources of transportation funding, those selected in the LRTP or the TIP may be opportunistic, constraining the ability of a region to fully implement plans truly consistent with its visioning (17).

Intermodal Surface Transportation Act (ISTEA) of 1991 brought about many changes in MPO decision-making. ISTEA provided funding for MPOs to carry out planning and codified criteria for transportation project selection. The law imposed the fiscal restraint requirement, requiring MPOs to work in partnership with state agencies over planning and funding (13). ISTEA also required that MPOs plan with respect to federally-defined planning factors, such as economic vitality and user safety, which have evolved over time in subsequent legislation (18). The two most recent transportation bills, MAP-21 and the FAST Act, now also require the planning process to assess performance management of the transportation system, establishing goals for factors such as infrastructure condition, congestion reduction and environmental sustainability (19). Because these performance measures have only recently been defined, few examples of how they have been used to guide project selection are available. But in one study of state DOTs, representatives reported interest but difficulty in making project selections based on performance metrics because formula funds tied to specific types of infrastructure constrained their ability to evaluate projects in a mode-neutral manner (20). Another challenge of using performance measures for project selection is that "what gets counted counts." MPOs may view the projects that meet quantifiable goals more favorably, entrenching familiar assessments in decision making (20).

\section{Equity in regional transportation planning}

While equity is not one of the named planning factors or performance measures mandated by USDOT, many MPOs nevertheless have adopted transportation equity as a guiding goal. The goals seek to address historical and racially-motivated injustices that have led to disparities in access to opportunities, health, and other life outcomes related to transportation decisions (2). On top of any guiding principles, federal regulations emanating from Title VI of the Civil Rights Act of 1964 and the Environmental Justice (EJ) executive order require MPOs to conduct equity-based analyses on LRTPs and TIPs to ensure that people of color, low-income people, and other protected groups are neither disproportionately burdened nor denied the benefits of transportation investments. However, scholars have critiqued these analyses for being perfunctory and not sufficient to eliminate inequities - just enough to ensure conditions get no worse but not enough to ensure they get better $(1,21,22)$.

Accessibility, on the other hand, is included among the federal planning factors and some MPOs have taken to using measures of accessibility in their EJ analyses (23). Accessibility is the ease with which people can reach their destinations and considers measures such as how many opportunities are within a certain distance or travel time $(24,25)$. Scholars have argued that because the goal of the transportation system is access rather than mobility - that is, connecting people to destinations rather than ensuring free-flow traffic-accessibility is the primary criterion by which transportation equity should be judged $(9,12,23,26,27)$. Others have argued that even a focus on accessibility for equity is too narrowly limited to questions of distributional justice; a fuller notion of mobility justice would redress the multiple ways that marginalized groups have been excluded from participating in planning processes $(28,29)$.

How organizations incorporate equity into performance analysis or project prioritization across planning organizations is inconsistent at best and absent at worst. Equity is often not fully operationalized and in many cases is prioritized lower than other goals, such as environmental 
sustainability or congestion reduction (10). And when equity is considered, measurement can be cursory. For example, a review of active transportation plans found that where equity was centered in the planning process, it focused largely on access to facilities rather than access to destinations or higher-order objectives (30). Smaller MPOs face additional challenges in that limited staff support and capability can render impossible the implementation of quantitative equity metrics, yielding vague notions of the equitable impacts of planning projects (11).

\section{METHODS}

This research examines how MPOs consider transportation equity in their short-term transportation investment decisions. We reviewed documentation from the 40 largest MPOs by population, all serving urbanized areas with over 1 million people (Table 1). We focused on the largest agencies because we expected them to have the capacity to consider more complex approaches to equity in project prioritization. We examined project prioritization methodologies to determine if MPOs considered equity as a criterion for allocating transportation funds. We considered equity criteria as any evaluation measure used in project prioritization that awarded or subtracted points to proposed projects based on the effects they would have on historically marginalized populations.

MPO project evaluation methodologies were available in several types of documents: the body or the appendixes of the most recent LRTPs; the most recent TIPs and their related development policies and project evaluation frameworks; policies for managing an MPO's attributable funds; and application and evaluation guidelines for regional calls for projects or for allocating transportation funding sources like the Surface Transportation Block Grant Program (STBGP), the Congestion Mitigation and Air Quality Improvement (CMAQ) Program, and the Transportation Alternatives Program (TAP). Most documents were available on MPO websites. We also contacted MPO staff members to request missing.

We obtained information about project prioritization from 34 of the 40 selected MPOs (Table 1, Column 4). Four MPOs did not prioritize or select projects for any funding source or inclusion in the TIP, but instead compiled the TIP based on recommendations from the member implementing agencies or transportation commissions. The remaining 30 had a project prioritization process for some funding sources (like STBG, CMAQ, and TAP) or inclusion in the TIP, of which 24 included equity-related criteria in their methodologies (Table 1, Column 5).

We evaluated and categorized the equity criteria for each of the 24 MPOs used based on their potential effectiveness in improving outcomes and representation in transportation decision making among groups historically marginalized from planning processes. The evaluation was based on a definition of transportation equity drawn from the literature reviewed earlier, which considered the following four components:

- distributing benefits and burdens of transportation projects, plans and policies between individuals and groups that differ by race, income, and ability;

- protecting and increasing the benefits - with an emphasis on accessibility-for historically marginalized populations, especially low-income communities of color;

- allocating resources based on communities' needs, with the aim of correcting existing differences and removing the effects of past discrimination; and

- providing effective opportunities for disadvantaged populations to participate in the transportation decisions that would affect them. 
1 TABLE 1 Metropolitan Planning Organizations and project prioritization analyzed

\begin{tabular}{|c|c|c|c|c|c|}
\hline \multirow[b]{2}{*}{ MPO } & \multirow[b]{2}{*}{ Urban centers } & \multirow{2}{*}{$\begin{array}{l}2010 \\
\text { Population } \\
\text { [millions] }\end{array}$} & \multicolumn{3}{|r|}{ Project Prioritization } \\
\hline & & & $\begin{array}{l}\text { MPO } \\
\text { defined? }\end{array}$ & $\begin{array}{l}\text { Equity } \\
\text { criteria? }\end{array}$ & Source document(s) \\
\hline SCAG & Los Angeles, CA & 18.1 & No & $\mathrm{N} / \mathrm{A}$ & $\mathrm{N} / \mathrm{A}$ \\
\hline NYMTC & New York, NY & 12.4 & No & $\mathrm{N} / \mathrm{A}$ & N/A \\
\hline CMAP & Chicago, IL & 8.5 & Yes & Yes & STP Shared Fund (FFY2020-2024) Program Application Booklet \\
\hline MTC & San Francisco, CA & 7.2 & Yes & Yes & $\begin{array}{l}\text { Horizon/Plan Bay Area 2050: Revised Project Performance Assessment } \\
\text { Methodology }\end{array}$ \\
\hline NJTPA & Newark, NJ & 6.6 & Yes & Yes & TIP NJTPA Project Prioritization Criteria \\
\hline NCTCOG & Dallas/Fort Worth, TX & 6.4 & Yes & Yes & $\begin{array}{l}\text { Transportation Alternatives Set-Aside Program } 2019 \text { Call for Projects for the } \\
\text { North Central Texas Region Project Evaluation and Scoring Ranges }\end{array}$ \\
\hline $\mathrm{H}-\mathrm{GAC}$ & Houston, TX & 5.9 & Yes & Yes & H-GAC 2018 Call for Projects Rules \\
\hline DVRPC & Philadelphia, PA & 5.6 & Yes & Yes & $\begin{array}{l}\text { Connections } 2045 \text { Plan for Greater Philadelphia, Appendix D: Project } \\
\text { Evaluation }\end{array}$ \\
\hline TPB & Washington, DC & 5.1 & No & $\mathrm{N} / \mathrm{A}$ & N/A \\
\hline ARC & Atlanta, GA & 4.8 & Yes & Yes & The ARC TIP Project Evaluation Framework Fall 2018 \\
\hline SEMCOG & Detroit, MI & 4.7 & No & $\mathrm{N} / \mathrm{A}$ & N/A \\
\hline MAG & Phoenix, AZ & 4.1 & No data & $\mathrm{N} / \mathrm{A}$ & $\mathrm{N} / \mathrm{A}$ \\
\hline PSRC & Seattle, WA & 3.7 & Yes & Yes & 2018 Regional Project Evaluation Criteria For PSRC's FHWA Funds \\
\hline Boston Region MPO & Boston, MA & 3.2 & Yes & Yes & Evaluation Criteria for FFYs 2020-24 TIP Development \\
\hline SANDAG & San Diego, CA & 3.1 & Yes & Yes & $\begin{array}{l}\text { San Diego Forward The } 2019 \text { Federal RTP, Appendix M: Transportation } \\
\text { Project Evaluation Criteria and Rankings }\end{array}$ \\
\hline Metropolitan Council & Saint Paul, MN & 2.9 & Yes & Yes & $\begin{array}{l}2020 \text { Regional Solicitation Applications, Traffic Management Technologies - } \\
\text { Prioritizing Criteria and Measures }\end{array}$ \\
\hline DRCOG & Denver, $\mathrm{CO}$ & 2.8 & Yes & Yes & $\begin{array}{l}\text { Policy on Transportation Improvement Program (TIP) Preparation, } \\
\text { Procedures for preparing the 2020-2023 TIP, Appendix D Regional Share } \\
\text { Criteria }\end{array}$ \\
\hline BRTB & Baltimore, MD & 2.7 & Yes & Yes & $\begin{array}{l}\text { Maximize2045: A Performance-Based Transportation Plan, Appendix B: } \\
\text { Project Evaluation and Scoring }\end{array}$ \\
\hline SPC & Pittsburgh, PA & 2.6 & No data & $\mathrm{N} / \mathrm{A}$ & $\mathrm{N} / \mathrm{A}$ \\
\hline EWGCOG & Saint Louis, MO & 2.6 & Yes & Yes & $\begin{array}{l}\text { STBG Program, } 2019 \text { Call for Projects For the St. Louis Region, Guidance } \\
\text { Document for STP-S Project Evaluation }\end{array}$ \\
\hline
\end{tabular}




\begin{tabular}{|c|c|c|c|c|c|}
\hline Miami Dade TPO & Miami, FL & 2.6 & No data & N/A & N/A \\
\hline SACOG & Sacramento, CA & 2.3 & Yes & No & $\begin{array}{l}2019 \text { Regional Funding Policy Framework Sacramento, Sutter, Yolo, Yuba } \\
\text { Counties }\end{array}$ \\
\hline NOACA & Cleveland, $\mathrm{OH}$ & 2.1 & No data & N/A & N/A \\
\hline AAMPO & San Antonio, TX & 2.0 & Yes & No & Scoring Criteria for TAP Project Call 206 \\
\hline OKI & Cincinnati, $\mathrm{OH}$ & 2.0 & Yes & Yes & $\begin{array}{l}\text { CMAQ Call for Projects/Programs, Overview Presentation, 2018; STP-MM } \\
\text { Project Call } 2018 \text { Final for Boards; Scoring Criteria for TAP Project Call } \\
2016\end{array}$ \\
\hline RTC & Las Vegas, NV & 2.0 & Yes & No & $\begin{array}{l}\text { Development of The Project Evaluation and Selection Process \& The } \\
\text { Congestion Management Process September } 2009\end{array}$ \\
\hline SEWRPC & Milwaukee, WI & 1.9 & Yes & No & $\begin{array}{l}\text { Commission Staff Procedure for Rating Candidate Projects for Federal } \\
\text { CMAQ Improvement Program Funding; Evaluation and Prioritization of } \\
\text { Candidate Projects for Years 2023-2025 Federal STBG Program; Selection of } \\
\text { Projects in the Milwaukee Urbanized Area for Federal Transportation } \\
\text { Alternatives Funding: 2023-2024 }\end{array}$ \\
\hline MARC & Kansas City, MO & 1.9 & Yes & Yes & $\begin{array}{l}\text { Call for Projects: Kansas City Metropolitan Region Federal Fiscal Years } \\
\text { 2023-2024 Kansas \& Missouri Surface Transportation Block Grant Program } \\
\text { (STBG) Funds }\end{array}$ \\
\hline MetroPlan Orlando & Orlando, FL & 1.8 & No data & N/A & N/A \\
\hline CAMPO & Austin, TX & 1.8 & Yes & Yes & 2019-2022 Project Call, Project Selection Criteria \\
\hline BMPO & Fort Lauderdale, FL & 1.7 & Yes & Yes & Commitment 2045 MTP, Technical Report \#4 Project Prioritization Process \\
\hline HRTPO & Chesapeake, VA & 1.6 & Yes & No & $\begin{array}{l}\text { HRTPO Prioritization Tool Scoring Criteria October 2013; Guide to the } \\
\text { HRTPO CMAQ and RSTP Project Selection Process March } 2018\end{array}$ \\
\hline WFRC & Salt Lake, UT & 1.6 & Yes & Yes & 2019-2050 RTP Wasatch Choice, Appendix M Needs-Based Phasing Criteria \\
\hline Indianapolis MPO & Indianapolis, IN & 1.6 & Yes & No & Indianapolis MPO TIP Project Selection Criteria May 2018 \\
\hline METRO & Portland, OR & 1.5 & Yes & Yes & $\begin{array}{l}\text { 2022-24 Regional Flexible Funds Allocation Project Evaluation Process and } \\
\text { Next Steps }\end{array}$ \\
\hline GNRC & Nashville, TN & 1.5 & Yes & Yes & 2016-2040 RTP, Appendix E. Project Evaluation Documentation \\
\hline MORPC & Columbus, $\mathrm{OH}$ & 1.4 & Yes & Yes & Policies for Managing MORPC-Attributable Funds, April 2018 \\
\hline Palm Beach TPA & West Palm Beach, FL & 1.3 & Yes & Yes & $\begin{array}{l}2020 \text { Local Initiatives (LI) Program Overview; } 2020 \text { Transportation } \\
\text { Alternatives (TA) Program Overview }\end{array}$ \\
\hline North Florida TPO & Jacksonville, FL & 1.3 & No data & N/A & N/A \\
\hline CRTPO & Charlotte, $\mathrm{NC}$ & 1.3 & Yes & Yes & 2045 CRTPO MTP, Appendix H: Project Ranking Methodologies \\
\hline
\end{tabular}




\section{RESULTS: EQUITY-ORIENTED PROJECT PRIORITIZATION CRITERIA}

The project selection methodologies of the 24 MPOs included transportation equity measures in different ways. Most incorporated specific equity criteria-commonly designated "Environmental Justice" or "Equity" - and a few considered equity within broader categories that combined different goals like environment and land use. Most addressed equity spatially; that is, whether projects were located in predefined areas with high concentrations of marginalized populations, sometimes known as communities of concern (e.g. 31). We categorized the various criteria used for prioritization into the following six types:

- Location burdens-based: considers the location of a project within communities of concern as detrimental for them; awards points if a project is not located within these areas or if measures to mitigate harm are integrated.

- Location benefits-based: considers the proximity of a project to communities of concern as beneficial for them; awards points if the project is located within or adjacent to them.

- Impacts-based: evaluates the potential benefits and burdens a project will have on communities of concern; awards more points to projects that will have positive effects and might subtract points from projects that will have negative effects.

- Access to destinations-based: considers accessibility improvements that projects provide to communities of concern and awards more points to projects that will provide greater increases in access to key destinations.

- User-based: consider who will use a proposed project, awarding a higher number of points if more people from communities of concern travel the facility.

- Community-engagement based: considers how project sponsors involved communities of concern prior to and during a project's development and awards more points to projects that show stronger community participation efforts.

The first five categories constitute a continuum of increasing potential for impact and increasing sophistication of calculation (Figure 1). The first type, location burdens-based, only focuses on mitigating harm, whereas the following categories, ordered by growing complexity, focus on improving transportation conditions for historically marginalized populations. The first four involve a spatial component as a proxy for users of a facility. They assess a facility as equitable to a community based on whether it is located in or near a community of concern, rather than an actual measure of use by these populations for which benefits are desired or burdens are prevented. These measures require only geographic (i.e., TAZ, census tracts, block groups, etc.) and demographic data, most of which are publicly available. For impact-based measures, geographic and demographic data are complemented with additional analyses that can be simply subjective judgements or require additional specifics. The fifth type, user-based, is placed at the end of the spectrum for several reasons. Unlike the previous categories, it measures which projected users of a transportation improvement belong to traditionally marginalized groups rather than a using spatial proxy. This type goes beyond simple geographic and demographic analyses, requiring travel demand modeling outputs for its calculation. User-based criteria also directly establish whether historically marginalized groups will benefit from investments.

The last type, community-engagement based, stands apart from the continuum as it does not measure aspects of the project itself, but of the planning process. Community-engagement criteria can also have a varying degree of complexity and potential for impact depending on how 


\section{Krapp, Barajas, Wennink}

1 authentic and transparent the engagement is and how it is measured. They can also enhance or

2 detract from the equity criteria in the other five categories.

3 How MPOs implement the criteria are varied. Thirteen use only one of the six equity

4 criteria, most of which apply their criteria with the same weight across all project types. The

5 other 11 agencies use more than one. Within this group, seven employ a combination of two

6 criteria types and one a combination of three to evaluate different aspects of a singular project,

7 regardless of its nature. Three used different types of criteria for projects of different nature. Of

8 the MPOs that used multiple criteria, three allocated the same weight for all project types,

9 whereas eight varied the weight according to the type of project. The following sections discuss

10 each of the six criteria types in detail. Table 2 indicates which criteria each MPO uses in their

11 selection methodologies and Table 3 provides an example of each type. 
1 TABLE 2 Types of equity criteria employed by MPOs in project prioritization

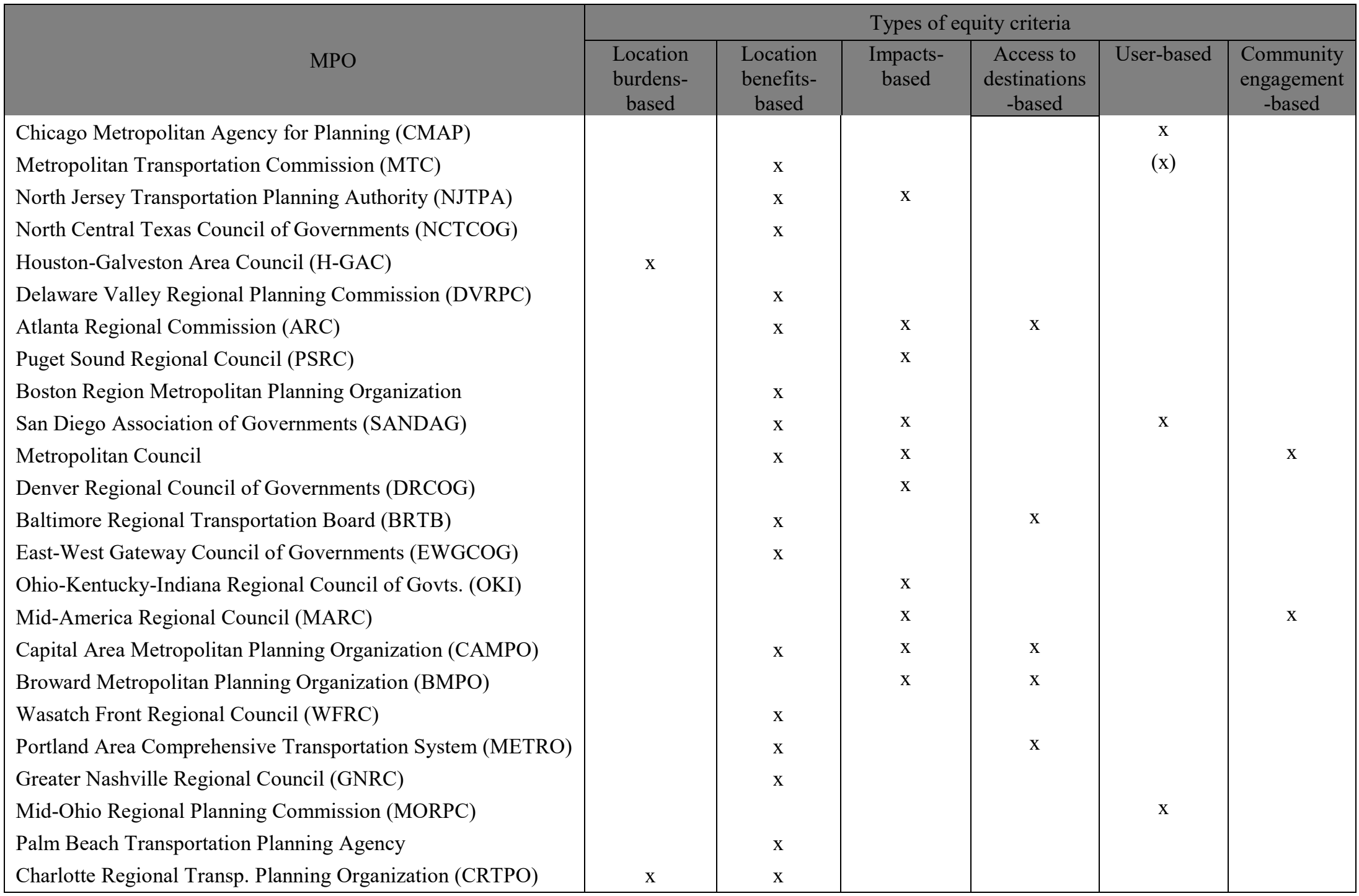

Note: MTC is in the process of adding a user-based criterion to its next LRTP. 


\begin{tabular}{|c|c|}
\hline Type & Example \\
\hline $\begin{array}{l}\text { Location } \\
\text { burdens- } \\
\text { based }\end{array}$ & $\begin{array}{l}\text { MPO: Houston-Galveston Area Council (H-GAC) } \\
\text { Project types: Manage, Maintain and Expand } \\
\text { Criterion: Environmental Justice, maximum weight of } 5 \% \text { of the total score } \\
\text { Definition and scoring: Projects will score } 10 \text { points if the proposed project is not located } \\
\text { in or adjoining environmental justice sensitive area or if the proposed project will } \\
\text { incorporate measures to reduce, minimize or avoid adverse effects on environmental } \\
\text { justice sensitive areas (census block groups) identified by HGAC }\end{array}$ \\
\hline $\begin{array}{l}\text { Location } \\
\text { benefits- } \\
\text { based }\end{array}$ & $\begin{array}{l}\text { MPO: East-West Gateway Council of Government (EWGCOG) } \\
\text { Project types: Road, Bridge, Traffic Flow, Safety, Active transportation, } \\
\text { Freight/Economic Development } \\
\text { Criterion: Addressing Social Equity, maximum weight of } 4 \% \text { of the total score } \\
\text { Definition and scoring: Project falls in, or partially in, an EJ area with high concentration } \\
\text { of: } \\
\text { - Low-income persons or minorities }=4 \text { points } \\
\text { - Zero-vehicle households }=3 \text { points } \\
\text { - Seniors or persons with a disability }=1 \text { point } \\
\text { - Project is not located in an EJ area or imposes a burden on an EJ area }=0 \text { points }\end{array}$ \\
\hline $\begin{array}{l}\text { Impacts- } \\
\text { based }\end{array}$ & $\begin{array}{l}\text { MPO: Broward Metropolitan Planning Organization (BMPO) } \\
\text { Project types: Highways, Transit, Systems Management/Safety } \\
\text { Criterion: Equity; maximum weight of } 3.6 \% \text { of the total score for each of the following } \\
\text { Definition and scoring: } \\
\text { Distribution of Transit Service Frequency: } \\
\text { - Project will add high-quality transit service to multiple new communities }=2 \text { points } \\
\text { - Project will add high-quality transit service to one new community }=1 \text { point } \\
\text { - Project will not add high-quality transit to any new communities }=0 \text { point } \\
\text { - Project may degrade transit service to a community }=-1 \text { point } \\
\text { Multimodal Safety within Equity Areas: } \\
\text { - Project will directly improve safety through improvements at a high-crash location } \\
\text { within an equity area }=2 \text { points } \\
\text {-Project may directly improve safety through improvements (regardless of existing crash } \\
\text { situation) within an equity area }=1 \text { point } \\
\text { - Project has no impact on safety within an equity area }=0 \text { points } \\
\text { - Project may introduce factors (higher speeds, higher traffic volumes, design features) } \\
\text { that could adversely impact multimodal safety within equity area = }-1 \text { point } \\
\text { Community Impacts: } \\
\text { - Project has no disproportionate impacts (physical and/or economic) on existing } \\
\text { residences or businesses = } 0 \text { points } \\
\text { - Project may have disproportionate impacts (physical and/or economic) on existing } \\
\text { residences or businesses = }-1 \text { points } \\
\text { - Project may have disproportionate impacts (physical and/or economic) on existing } \\
\text { residences or businesses within an equity area = }-2 \text { points }\end{array}$ \\
\hline
\end{tabular}




\begin{tabular}{|c|c|}
\hline $\begin{array}{c}\text { Access to } \\
\text { destinations- } \\
\text { based }\end{array}$ & $\begin{array}{l}\text { MPO: Atlanta Regional Commission (ARC) } \\
\text { Project types: Transit Expansion } \\
\text { Criterion: Social Equity, maximum weight of } 6 \% \text { of the total score } \\
\text { Definition and scoring: Change in the number of jobs that low-income and minority } \\
\text { community workers can access during peak period. The number of new low-income and } \\
\text { minority community workers with access to Regional Employment Centers will be } \\
\text { scored on a distribution to assign a range of scores from } 0-100 \text { based on area with low- } \\
\text { income and minority concentrations ranked as medium-high or high. The project with } \\
\text { the highest number of new workers gaining access will receive the highest score, the } \\
\text { project with the least will receive the lowest. }\end{array}$ \\
\hline User-based & $\begin{array}{l}\text { MPO: Chicago Metropolitan Agency for Planning (CMAP) } \\
\text { Project types: Road reconstructions, Transit station rehabilitation/reconstructions, Bridge } \\
\text { rehabilitation/reconstructions, Highway/rail grade crossing improvements, Road } \\
\text { expansions, Bus speed improvements, Corridor-level or small area safety improvements, } \\
\text { Truck route improvements } \\
\text { Criterion: Inclusive Growth, maximum weight of } 8 \% \text { of the total score } \\
\text { Definition and scoring: Percent of travelers using a facility that are people of color below } \\
\text { the poverty line, as modeled by CMAP's travel demand model } \\
\text { - } 0 \%-5 \% \text { of travelers }=0 \text { points } \\
\text { - } 5 \%-10 \% \text { of travelers }=2 \text { points } \\
\text { - } 10 \%-15 \% \text { of travelers }=4 \text { points } \\
\text { - } 15 \%-20 \% \text { of travelers }=6 \text { points } \\
\text { - } 20 \%-25 \% \text { of travelers }=8 \text { points } \\
\text { - } 25 \% \text { or more }=10 \text { points }\end{array}$ \\
\hline $\begin{array}{l}\text { Community- } \\
\text { engagement } \\
\text { based }\end{array}$ & $\begin{array}{l}\text { MPO: Mid-America Regional Council (MARC) } \\
\text { Project types: Bridge Restoration, Rehabilitation, \& Replacement; Bicycle/Pedestrian; } \\
\text { Public Transportation; Roadway Capacity; Transportation Operations and Management; } \\
\text { Transportation Safety } \\
\text { Criterion: Equity - Public Participation; maximum weight of approx. } 4 \% \text { of total score } \\
\text { Definition and scoring: } \\
\text { - Project implementation will include public engagement strategy. Strategy is } \\
\text { clearly described in attachment and includes specific techniques to engage } \\
\text { transportation disadvantaged populations }=5 \text { points } \\
\text { - Conceptual project underwent further planning and refinement in a process that } \\
\text { included public engagement and incorporated feedback received = } 3 \text { points } \\
\text { Project supports goals and strategies developed through a } \\
\text { comprehensive/general planning process that included public engagement and } \\
\text { incorporated feedback received = } 1 \text { points } \\
\text { No public participation cited and/or project does not support goals and strategies } \\
\text { in comprehensive/general plan }=0 \text { points }\end{array}$ \\
\hline
\end{tabular}


Krapp, Barajas, Wennink

\section{Location burdens-based criteria and location benefits-based criteria}

These categories assess equity simply based on the location of a proposed project. Location burdens-based criteria aim to capture potential negative effects of projects located within or near communities of concern, like those created by highways routed through lowincome neighborhoods. The criteria assume that burdens are intrinsic features of transportation projects. Only two MPOs adopted this approach. Neither penalizes projects by subtracting points for imposing burdens on disadvantaged populations. For example, H-GAC awards 5\% of the total score if a project either avoids an EJ sensitive area or reduces or avoids negative impacts if it is in an EJ sensitive area.

Location benefits-based criteria, conversely, consider projects to benefit underserved populations if the projects are geographically proximate to them. The criteria acknowledge the potential positive impacts of transportation projects that are nearby communities of concern and, therefore, which they are likely to use. Most MPOs assess projects in this way: 16 of the 24 MPOs that incorporate equity criteria measure location benefits. For example, EWGCOG awards points for projects located in an EJ area based on the concentration of various types of disadvantaged groups but awards no points if the project is not located in an EJ area. Other MPOs are more specific, either by scaling their scoring according to how concentrated disadvantaged groups are or by assessing the population in multiple buffer distances around the projects.

Location-based criteria are the types most widely used by MPOs, likely because they are easier to calculate than the others. These measures only require demographic data and mapping, whereas the others need a more comprehensive evaluation, complex data sets, and sophisticated tools such as travel demand models. Many MPOs categorize new transportation infrastructure near marginalized populations as conferring access benefits because they have access to more or improved transportation choices. But geographic access does not necessarily reflect the ability to use it.

\section{Impacts-based criteria}

Unlike location-based criteria, impacts-based criteria require a more detailed evaluation of a project's potential impacts to determine how beneficial or detrimental they will be for communities of concern. This type does not assume positive or negative effects solely because of proximity.

Ten MPOs used this type. Four agencies used quantitative measures, clearly defining which effects might qualify for points. For example, BMPO analyzes the distribution of transit service frequency, multimodal safety, and physical and economic impacts. BMPO awards points depending on the strength of positive impacts, they award zero points to projects without positive effects, and they subtract points from projects that generate burdens. The rest of the MPOs, conversely, adopt a more flexible approach requesting project sponsors to provide an assessment or evidence of how their projects will impact communities of concern, leaving the evaluation open-ended. All these MPOs ask sponsors to describe how their projects will improve conditions for EJ populations. One also asks them to describe the potential negative effects of their projects and mitigation measures to be implemented. This allows for a nuanced and context-specific evaluation of impacts but also increases subjectivity.

\section{Access to destinations-based}

Access to destinations is a kind of impacts-based type that considers how projects improve the ability to reach key locations — such as groceries, medical, and employment — for 
areas with high concentrations of disadvantaged population groups. The category includes measures that focus on how projects provide new, better, or faster access. The specificity of this analysis and the importance of transportation's essential function of providing access to basic needs suggests it belongs in a different category from impacts-based criteria.

Five MPOs used this criterion. All of them adopted approaches of varying complexity. For example, ARC defines an equity criterion for transit projects in terms of increased job access, reflecting a critical goal of connecting people with economic opportunity. However, the guidelines are unclear how access itself is calculated. BMPO considers connectivity improvements or travel time reductions between communities of concern and key activity centers and opportunities, prioritizing projects that allow communities to access destinations faster. BRTB performs a spatial analysis to determine the degree to which a transit project supports access to specific destinations for EJ populations. METRO leaves the assessment subjective and open-ended, requiring evaluators to consider how projects improve access to places that are most needed and meaningful to equity focus areas. CAMPO requests that project sponsors detail how transit or active transportation projects will enhance access to or within EJ zones by making new connections, reducing travel time, and increasing employment or educational opportunities.

\section{User-based criteria}

Whereas the previous categories rely on aggregate neighborhood characteristics or residential location to judge the potential equity impacts of projects, the user-based category considers the characteristics of the population directly served by a facility. Because they measure individual users rather than aggregated communities, user-based criteria require the use of travel demand models to predict travel behavior.

Three MPOs used this type. CMAP uses their travel demand model to measure what percentage of a facility's users would be people of color below the poverty line. Using the population share served rather than an absolute number of people is a choice that has implications for equity. A percentage might advantage projects sponsored by smaller communities over larger ones if they have fewer disadvantaged users that account for a larger fraction of facility users, whereas using the total number of users would likely benefit more populous municipalities. SANDAG adopts a different approach, using the increase in transit trips made by disadvantaged communities as a proxy for users. MTC's next plan update will add a user-based criterion, in which they will calculate a ratio of accessibility benefits experienced by low-income groups to the sum of accessibility benefits experienced by all income groups based on travel demand model outputs.

Because user-based criteria require sophisticated tools like travel demand models, MPOs without the capacity or capability to run advanced simulations may not be able to employ this category of measures in their prioritization process. Even when agencies can deploy them, models can be imprecise and limited by the assumptions built into the designs.

\section{Community engagement-based criteria}

Unlike the other categories, community engagement-based criteria examine the process by which projects are developed rather than the impacts of the projects themselves. Two MPOs used this type. Neither agency used this category in isolation, instead using it together with other analysis types.

The two MPOs that evaluated community engagement have different approaches. MARC awards an increasing number of points depending how public participation influences the stages of project development, from conception to implementation. It awards the maximum number of points for projects with clear strategies in place that include specific techniques to engage 


\section{Krapp, Barajas, Wennink}

transportation disadvantaged populations during implementation. It awards no points to projects without public participation. A limitation of MARC's criteria is that any public engagement qualifies for points, regardless of who the participants are, though maximum points are reserved for participation with disadvantaged groups. The Metropolitan Council's criterion is more flexible. It requests projects sponsors to describe the engagement methods and tools they used and the influence that community feedback had on the projects, awarding up to 20 points to be determined by the agency.

Prioritizing projects based on meaningful community engagement helps ensure that projects that have the potential to impact communities of concern will be shaped by them. It also holds sponsors accountable and responsible for involving historically marginalized groups in their planning efforts. However, assessing the level of engagement of disadvantaged communities solely based on the descriptions and records provided by project sponsors might not always accurately reflect their involvement and perspectives.

\section{TRANSPORTATION EQUITY IMPLICATIONS}

MPOs use a variety of criteria types to assess transportation equity in project prioritization. The criteria fell into five categories that ranged from burden avoidance to individual accessibility measures, plus a sixth that considered the project planning process. While most MPOs included equity in their project prioritization criteria, we argue that the methods could be improved to better align with broader definitions of transportation equity, focusing on how targeted groups are defined, more comprehensive methods for equity evaluation, and adjusting prioritization weights.

Agencies clearly defined disadvantaged groups in the prioritization criteria or in related documents. All included low-income people and people of color, while some also included other groups like people with disabilities and older adults. But most MPOs spatially identified communities of concern or environmental justice areas dichotomously, based on whether or not a neighborhood had high concentrations of the target populations. The method is simple to implement but has at least two drawbacks. First, the lived experiences and travel behavior of various underserved groups are different, so projects will impact them differently as well. A community with a significant Black population, for example, may be more likely to suffer from lack of transit connections between their homes and dispersed job sites, while a neighborhood with a senior living facility might benefit more from paratransit and localized pedestrian improvements. Second, the use of geographic units and static demographic thresholds as a proxy for underserved users does not work well for groups that do not cluster spatially, such as people with disabilities or single parents $(22,32)$.

Most MPOs did not use a comprehensive equity evaluation as part of their project prioritization; two thirds included only one type of equity criteria in their assessment. This limits the view of the potential impacts that projects could have because each of the six types focuses on a narrow set of aspects. Location burdens-based criteria consider burdens generally and do not account for potential project benefits. Location benefits-, access to destinations-, and userbased criteria focus each on specific positive effects, such as proximity, improved accessibility, and facility use, but fail to include many others, such as safety, environmental, and public health improvements. Most of the impacts-based criteria also neglected to acknowledge any potential burdens: over half of the MPOs that used impacts-based criteria focused solely on benefits. None of the measures included a quantitative assessment of community participation, and only two MPOs prioritized projects that engaged potential users. Individual transportation projects resist simple binaries of benefits and burdens. A roadway widening project, for example, may reduce 


\section{Krapp, Barajas, Wennink}

travel times on a congested link, thus improving accessibility to destinations for road users. But it may also increase traffic volume and thus local near-roadway emissions, harming those who live the closest to the facility. Even if environmental impacts are weighted under separate prioritization categories, a more comprehensive evaluation that spans criteria would grapple with these choices under an equity lens.

Access is the primary benefit of transportation systems, and most MPOs considered access in some way among their equity criteria. Two thirds of the MPOs used location benefitsbased criteria, equating proximity to facility to improving access. But access to facilities is not the same as access to destinations; a transportation improvement could be nearby yet present a multitude of barriers to use because of cost, household vehicle availability, connectivity, and others. Access to destinations-based criteria overcome this shortcoming, establishing how new infrastructure increases reach to key opportunities. However, the main limitation of both criteria types is that the real users of the facility may differ from those who are assumed to access the transportation project based on the spatial analysis.

A significant shortcoming of how most agencies implement prioritization criteria is the degree to which equity is weighted with respect to other criteria. Current weightings are not high enough to influence project evaluation significantly. For most MPOs, the maximum weighting of the equity criteria was less than $10 \%$ of the overall score-sometimes much less. Four MPOs were the exception: METRO and BMPO, with $25 \%$ and $14.3 \%$ of the total score devoted to the equity criteria they apply uniformly to all project types, and ARC and the Metropolitan Council, which applied approximately $14 \%$ of the total score to their equity criteria for transit projects. Even in these exceptional cases, a project that does not advance equity is still able to rank first by scoring high on other criteria that account for higher proportions of the total, such as mobility and congestion reduction, air quality, and safety.

This study examined MPOs because, due to federal rules, there is a consistent planning process at this scale that allows regional comparisons. However, MPOs do not control the majority of regional transportation funds, directly allocating only a small portion of money. To effect real impact, a wider range of institutions will need to implement stronger equity-focused prioritization processes.

\section{CONCLUSIONS AND RECOMMENDATIONS}

Transportation equity is a multifaceted concept and as such, its incorporation in planning and programming processes requires rigorous attention to deliberately influence the allocation of funding. We find that to achieve meaningful improvements for traditionally underserved groups, equity measures must be multidimensional and given more weight. Agencies should use multiple equity-oriented criteria to prioritize projects, focusing not only on mitigating harm but also on proactively improving transportation conditions and participation in planning processes for historically marginalized groups. Equity criteria should simultaneously consider benefits, burdens, and engagement for a holistic assessment of projects.

MPOs should go beyond location-based measures as their main prioritization criteria because they are limited in scope. They should clearly assess and prioritize both benefits and burdens of transportation projects in disaggregate with respect to race, income, ability, and geography, and provide clear guidance to project sponsors on evaluation. The contribution to increasing access to key destinations for traditionally underserved groups should always be assessed for projects, and those with potential negative effects for communities of concern should be penalized with point subtraction unless they incorporate measures to minimize or avoid them. Agencies could also require project sponsors to submit their own assessments of 


\section{Krapp, Barajas, Wennink}

how their projects would impact these communities. This would allow reviewers to understand effects that might not be captured by established scoring categories, which could then be awarded points. All methodologies should include community engagement-based criteria or some indicator of the extent of community support or opposition to proposed projects, whether projects address needs defined by members of the communities they intend to serve, and whether communities had a role in generating project concepts. Community input on preferred alternatives should be gathered very early in the process if communities do not explicitly cocreate solutions with the agency.

Critically, MPOs should adjust project weighting to more meaningfully target investments towards communities with higher needs. If equity criteria weights remain low, there is likely to be a minimal effect on the overall regional allocation of resources, thereby sustaining transportation inequities. Agencies should also conduct periodic regional analyses to monitor trends to evaluate whether outcomes for marginalized populations are improving. While TIPs are required to be updated every two years, thus subjecting proposed projects to relatively frequent review, evaluating travel forecast accuracy is not a priority in most cases $(33,34)$. An evaluation would reveal whether the equity criteria used are effective at improving outcomes for underserved populations. If not, or if change is progressing too slowly, the agency should revise its measures and weights to increase the focus on equity, although the effects of large scale infrastructure investments may not be known for some time.

Perhaps the biggest potential gain for equity goes beyond quantitative measures and assessments of engagement to reframing transportation inequities in terms of injustices. While MPOs in this study generally considered the benefits of transportation projects, few emphasized the protection of historically harmed population groups. Only three agencies penalized projects with negative effects by subtracting points. The two MPOs that used location burdens-based criteria to assess projects aimed to avoid negative impacts, but not to improve outcomes. Environmental justice regulations and civil rights law only go so far as to mandate that agencies prevent the denial of benefits or the disproportionate imposition of burdens, without requiring them to repair harm from decades of inequitable and racist planning. A complete treatment of justice-oriented transportation planning is beyond the scope of this paper, but in short, adopting prioritization criteria that ensure that projects first affirmatively remedy historical violations and work with affected communities to adopt appropriate and meaningful solutions is a step toward this reconceptualization. As a longer-term goal, these criteria might examine solutions to resolving injustices from other domains as well, such as housing affordability and employment barriers, given the complex causes of poverty and inequity in the US.

We have identified several areas for further research. First, this study was limited in scope to larger MPOs because we hypothesized their analytic capabilities would make them more likely to conduct sophisticated equity analyses. But smaller agencies may already be doing such work. For example, the Champaign County (IL) Regional Planning Commission created an access score, comprised of indices for level of traffic stress by mode, access to key destinations, and health impact assessment, to guide equitable investment. Additional work should examine how smaller and rural MPOs incorporate equity into their planning processes to identify ways that agencies with fewer resources might achieve similar goals. We were also limited to examining public documents and other data that were available on agency websites or via email. Those documents did not detail the reasons why MPOs undertook particular analyses, for example, or the constraints they may have faced in addressing equity concerns. Interviews with planning staff would further inform recommendations in the face of structural challenges we did not explore here. Finally, we did not explore how the development of equity metrics compared to other planning goals, like environmental impacts or public health outcomes. The relative 
Krapp, Barajas, Wennink

investment in developing analysis tools could be instructive in revealing an agency's capacity constraints or the priority they place on equity-first planning.

\section{ACKNOWLEDGMENTS}

The authors wish to thank Jeremy Glover, Kate Lowe, and Olatunji Oboi Reed for their guidance and input. We also thank the two anonymous reviewers of the TRB Annual Meeting conference paper for their helpful comments.

\section{AUTHOR CONTRIBUTIONS}

The authors confirm contribution to the paper as follows: study conception and design: A. Krapp, A. Wennink; data collection: A. Krapp; analysis and interpretation of results: A. Krapp,

J. Barajas, A. Wennink; draft manuscript preparation: A. Krapp, J. Barajas. All authors reviewed the results and approved the final version of the manuscript.

\section{REFERENCES}

1. Sanchez, T. W., R. Stolz, and J. S. Ma. Moving to Equity: Addressing Inequitable Effects of Project of Harvard University, 2003.

2. Bullard, R. D. The Anatomy of Transportation Racism. In Highway Robbery (R. D. Bullard, G. S. Johnson, and A. O. Torres, eds.), South End Press, pp. 15-32.

3. Grengs, J. The Abandoned Social Goals of Public Transit in the Neoliberal City of the USA. City, Vol. 9, No. 1, 2005, pp. 51-66. https://doi.org/10.1080/13604810500050161.

4. Rothstein, R. The Color of Law: A Forgotten History of How Our Government Segregated America. Liveright Publishing Corporation, New York; London, 2017.

5. Marcantonio, R. A., A. Golub, A. Karner, and L. Nelson. Confronting Inequality in Metropolitan Regions: Realizing the Promise of Civil Rights and Environmental Justice in Metropolitan Transportation Planning. Fordham Urban Law Journal, Vol. 44, No. 4, 2017, p. 1017.

6. US Department of Transportation. DOT Order 5610.2(a). https://www.fhwa.dot.gov/environment/environmental_justice/ej_at_dot/orders/order_5610 2a/index.cfm. Accessed Jul. 6, 2020.

7. Federal Transit Administration. Title VI Requirements and Guidelines for Federal Transit Administration Recipients. https://www.transit.dot.gov/sites/fta.dot.gov/files/docs/FTA_Title_VI_FINAL.pdf. Accessed Jul. 6, 2020.

8. Handy, S. Regional Transportation Planning in the US: An Examination of Changes in Technical Aspects of the Planning Process in Response to Changing Goals. Transport Policy, Vol. 15, No. 2, 2008, pp. 113-126. https://doi.org/10.1016/j.tranpol.2007.10.006.

9. Golub, A., and K. Martens. Using Principles of Justice to Assess the Modal Equity of Regional Transportation Plans. Journal of Transport Geography, Vol. 41, 2014, pp. 10-20. https://doi.org/10.1016/j.jtrangeo.2014.07.014.

10. Manaugh, K., M. G. Badami, and A. M. El-Geneidy. Integrating Social Equity into Urban Transportation Planning: A Critical Evaluation of Equity Objectives and Measures in Transportation Plans in North America. Transport Policy, Vol. 37, 2015, pp. 167-176. https://doi.org/10.1016/j.tranpol.2014.09.013. 
Krapp, Barajas, Wennink

11. Karner, A. Planning for Transportation Equity in Small Regions: Towards Meaningful Performance Assessment. Transport Policy, Vol. 52, 2016, pp. 46-54. https://doi.org/10.1016/j.tranpol.2016.07.004.

12. Pereira, R. H. M., T. Schwanen, and D. Banister. Distributive Justice and Equity in Transportation. Transport Reviews, Vol. 37, No. 2, 2017, pp. 170-191. https://doi.org/10.1080/01441647.2016.1257660.

13. Goldman, T., and E. Deakin. Regionalism Through Partnerships? Metropolitan Planning Since ISTEA. Berkeley Planning Journal, Vol. 14, No. 1, 2000. https://doi.org/10.5070/BP314112983.

14. BATIC Institute: An AASHTO Center for Excellence. Funding. Transportation Funding and Financing. http://www.financingtransportation.org/funding_financing/funding/. Accessed Nov. 19, 2020.

15. Eno Center for Transportation. Transportation at the Ballot Box 2018. https://www.enotrans.org/transportation-at-the-ballot-box-2018/. Accessed Nov. 19, 2020.

16. Lowe, K. Bypassing Equity? Transit Investment and Regional Transportation Planning. Journal of Planning Education and Research, Vol. 34, No. 1, 2014, pp. 30-44. https://doi.org/10.1177/0739456X13519474.

17. Lowe, K., and G.-C. Sciara. Chasing TIGER: Federal Funding Opportunities and Regional Transportation Planning. Public Works Management \& Policy, Vol. 23, No. 1, 2018, pp. 78-97. https://doi.org/10.1177/1087724X17732583.

18. Sciara, G.-C. Metropolitan Transportation Planning: Lessons From the Past, Institutions for the Future. Journal of the American Planning Association, Vol. 83, No. 3, 2017, pp. 262276. https://doi.org/10.1080/01944363.2017.1322526.

19. Federal Highway Administration. Performance Management. MAP-21 - Moving Ahead for Progress in the 21st Century. https://www.fhwa.dot.gov/map21/factsheets/pm.cfm. Accessed Jul. 3, 2020.

20. Sperling, E., and C. Ross. Strategically Aligning Capital Improvement Prioritization to Performance Goals. Transportation Research Record, Vol. 2672, No. 51, 2018, pp. 68-78. https://doi.org/10.1177/0361198118787639.

21. Martens, K., A. Golub, and G. Robinson. A Justice-Theoretic Approach to the Distribution of Transportation Benefits: Implications for Transportation Planning Practice in the United States. Transportation Research Part A: Policy and Practice, Vol. 46, No. 4, 2012, pp. 684-695. https://doi.org/10.1016/j.tra.2012.01.004.

22. Karner, A., and D. Niemeier. Civil Rights Guidance and Equity Analysis Methods for Regional Transportation Plans: A Critical Review of Literature and Practice. Journal of Transport Geography, Vol. 33, 2013, pp. 126-134. https://doi.org/10.1016/j.jtrangeo.2013.09.017.

23. Boisjoly, G., and A. M. El-Geneidy. How to Get There? A Critical Assessment of Accessibility Objectives and Indicators in Metropolitan Transportation Plans. Transport Policy, Vol. 55, 2017, pp. 38-50. https://doi.org/10.1016/j.tranpol.2016.12.011.

24. Hansen, W. G. How Accessibility Shapes Land Use. Vol. 25, No. 2, 1959, pp. 73-76. https://doi.org/10.1080/01944365908978307.

25. Handy, S. L., and D. A. Niemeier. Measuring Accessibility: An Exploration of Issues and Alternatives. Environment and Planning A, Vol. 29, No. 7, 1997, pp. 1175-1194. https://doi.org/10.1068/a291175.

26. Martens, K. Transport Justice: Designing Fair Transportation Systems. Routledge, Taylor \& Francis Group, New York, NY, 2017. 
Krapp, Barajas, Wennink

27. Martens, K., and A. Golub. A Fair Distribution of Accessibility: Interpreting Civil Rights Regulations for Regional Transportation Plans. Journal of Planning Education and Research, 2018, p. 0739456X18791014. https://doi.org/10.1177/0739456X18791014.

28. Sheller, M. Mobility Justice: The Politics of Movement in the Age of Extremes. Verso, London; Brooklyn, NY, 2018.

29. Karner, A., J. London, D. Rowangould, and K. Manaugh. From Transportation Equity to Transportation Justice: Within, Through, and Beyond the State. Journal of Planning Literature, 2020, p. 0885412220927691. https://doi.org/10.1177/0885412220927691.

30. Lee, R. J., I. N. Sener, and S. N. Jones. Understanding the Role of Equity in Active Transportation Planning in the United States. Transport Reviews, Vol. 37, No. 2, 2017, pp. 211-226. https://doi.org/10.1080/01441647.2016.1239660.

31. Metropolitan Transportation Commission, and Association of Bay Area Governments. Plan Bay Area 2040: Final Equity Analysis Report. San Francisco, CA, 2017, p. 133.

32. Rowangould, D., A. Karner, and J. London. Identifying Environmental Justice Communities for Transportation Analysis. Transportation Research Part A: Policy and Practice, Vol. 88, 2016, pp. 151-162. https://doi.org/10.1016/j.tra.2016.04.002.

33. Flyvbjerg, B., M. K. S. Holm, and S. L. Buhl. How (In)Accurate Are Demand Forecasts in Public Works Projects?: The Case of Transportation. Journal of the American Planning Association, Vol. 71, No. 2, 2005, pp. 131-146. https://doi.org/10.1080/01944360508976688.

34. Hartgen, D. T. Hubris or Humility? Accuracy Issues for the next 50 Years of Travel Demand Modeling. Transportation, Vol. 40, No. 6, 2013, pp. 1133-1157. https://doi.org/10.1007/s11116-013-9497-y. 
Krapp, Barajas, Wennink

1

2

FIGURE 1 Categorization of MPO equity criteria 